Policy Research Working Paper 5095

Background Paper to the 20 io World Development Report

\title{
A Polycentric Approach for Coping with Climate Change
}

\author{
Elinor Ostrom
}

The World Bank

Development Economics

Office of the Senior Vice President and Chief Economist

October 2009 
Policy Research Working Paper 5095

\begin{abstract}
This paper proposes an alternative approach to addressing the complex problems of climate change caused by greenhouse gas emissions. The author, who won the 2009 Nobel Prize in Economic Sciences, argues that single policies adopted only at a global scale are unlikely to generate sufficient trust among citizens and firms so that collective action can take place in a comprehensive and transparent manner that will effectively reduce global warming. Furthermore, simply recommending a single governmental unit to solve global collective action problems is inherently weak because of freerider problems. For example, the Carbon Development Mechanism (CDM) can be 'gamed' in ways that hike up prices of natural resources and in some cases can lead to further natural resource exploitation. Some flaws are also noticeable in the Reducing Emissions from Deforestation and Forest Degradation in Developing Countries (REDD) program. Both the CDM and REDD are vulnerable to the free-rider problem. As an alternative, the paper proposes a polycentric approach at various levels with active oversight of local, regional, and

national stakeholders. Efforts to reduce global greenhouse gas emissions are a classic collective action problem that is best addressed at multiple scales and levels. Given the slowness and conflict involved in achieving a global solution to climate change, recognizing the potential for building a more effective way of reducing green house gas emissions at multiple levels is an important step forward. A polycentric approach has the main advantage of encouraging experimental efforts at multiple levels, leading to the development of methods for assessing the benefits and costs of particular strategies adopted in one type of ecosystem and compared to results obtained in other ecosystems. Building a strong commitment to find ways of reducing individual emissions is an important element for coping with this problem, and having others also take responsibility can be more effectively undertaken in small- to medium-scale governance units that are linked together through information networks and monitoring at all levels. This paper was prepared as a background paper for the 2010 World Development Report on Climate Change.
\end{abstract}

This paper-prepared as a background paper to the World Bank's World Development Report 2010: Development in a Changing Climate - is a product of the Development Economics Vice Presidency. The views expressed in this paper are those of the authors and do not reflect the views of the World Bank or its affiliated organizations. Policy Research Working Papers are also posted on the Web at http://econ.worldbank.org. The author may be contracted at research@worldbank.org.

The Policy Research Working Paper Series disseminates the findings of work in progress to encourage the exchange of ideas about development issues. An objective of the series is to get the findings out quickly, even if the presentations are less than fully polished. The papers carry the names of the authors and should be cited accordingly. The findings, interpretations, and conclusions expressed in this paper are entirely those of the authors. They do not necessarily represent the views of the International Bank for Reconstruction and Development/World Bank and its affiliated organizations, or those of the Executive Directors of the World Bank or the governments they represent. 


\title{
A POLYCENTRIC APPROACH FOR COPING WITH CLIMATE CHANGE
}

\author{
by
}

\section{Elinor Ostrom}

Workshop in Political Theory and Policy Analysis

Indiana University

Center for the Study of Institutional Diversity

Arizona State University

Report prepared for the WDR2010 Core Team, Development and Economics Research Group, World Bank, 1818 H Street NW, Washington, DC 20433. Thanks to Jimmy Walker for several discussions of the questions raised in this report and to Patty Lezotte for her excellent editing help and to the National Science Foundation for research support.

\section{Workshop in Political Theory and Policy Analysis}

\author{
Indiana University, 513 North Park, Bloomington, IN 47408-3895 USA
}

812.855.0441 / fax: 812.855.3150 / workshop@indiana.edu / www.indiana.edu/ workshop 


\title{
A POL YCENTRIC APPROACH FOR COPING WITH CLIMATE CHANGE
}

\author{
Elinor Ostrom
}

\section{The Challenge of Climate Change}

Richard Meserve, President of the Carnegie Institution of Washington and former Chairman of the U.S. Nuclear Regulatory Commission, opened a panel on Global Change at the October 7, 2007, Stated Meeting of the American Academy of Arts and Sciences with several warnings about the severity and diversity of effects that are predicted by the Intergovernmental Panel on Climate Change (2007). Meserve (2008: 31) stressed that "climate change is a severe challenge that no one country can solve.” Rosina Bierbaum, Dean of the School of Natural Resources and Environment at the University of Michigan, in her own excellent analysis of the problem, also stressed the imminent dangers that the world was facing due to melting glaciers, rising sea levels, reduced food supplies, as well as the expected increases in extreme events that climate change was stimulating.

Instead of focusing primarily on the need for a global solution, Bierbaum (2008: 34) stressed that adaptation research has been lagging and that we "are not making progress in understanding vulnerability to climate change and its potential impacts on humans, conducting risk analysis, or understanding what stakeholders want from science to aid decision making." In addition to the excellent research agenda outlined by Bierbaum, it is also essential that substantial research reexamine Meserve's view that solutions to global change must be global in scale. I agree with him that "no one country can solve" the global climate change problem by 
acting alone. If only one country in the world tried to solve climate change-even one of the wealthier countries of the world — this would be a grossly inadequate effort.

\section{Must We Wait for a Global Solution?}

Waiting for a single worldwide "solution" to emerge from global negotiations is also problematic. The Kyoto Protocol to the United Nations Framework Convention on Climate Change (UNFCCC or FCCC) is an international environmental treaty created and signed at the Conference of the Parties of the UNFCC in Kyoto in 1997. While more than 180 countries have ratified the Protocol, the United States has not. Further, considerable disagreements exist even among the major states that have signed as to how large a reduction in emissions is required (Matthews and Caldeira, 2008).

Major debates exist over a number of key issues related to achieving efficient and fair mechanisms at a global level. One relates to who is responsible for the current and immediate future levels of carbon dioxide $\left(\mathrm{CO}_{2}\right)$ in the atmosphere (Botsen et al., 2008; Dellink et al., 2009; den Elzen et al., 2005). This is related to who should bear the primary burden of paying for solutions (Najam et al., 2003; Baer et al., 2000; Posner and Sunstein, 2008). Other debates relate to whether or not various "remedies" proposed to reduce carbon sequestration contribute to helping solve other environmental concerns. One puzzle is related to whether deforestation contributes to climate change primarily through releases of $\mathrm{CO}_{2}$ to the atmosphere or whether changes in land cover, evapotranspiration, and cloud cover are as important and must be taken into account when planning afforestation efforts (Bala et al., 2007). Similarly, scholarly concerns have been raised about claims that Payments for Ecosystem Services (PES) can jointly increase carbon sequestration and enhance species conservation on the same landscape (Nelson et al., 2008). 
Given the decades-long failure at an international level to reach agreement on efficient, fair, and enforceable reductions of greenhouse gas emissions, continuing to wait may defeat the possibilities of significant adaptations and mitigations in time to prevent tragic disasters. Further, given the importance of technological change, without numerous innovative technological and institutional efforts at multiple scales, we may not even begin to learn which combined sets of actions are the most effective in reducing the long-term threat of massive climate change.

In addition to the problem of waiting too long, "global solutions" negotiated at a global level, if not backed up by a variety of efforts at national, regional, and local levels, however, are not guaranteed to work well. While the level of $\mathrm{CO}_{2}$ and other greenhouse gases in the atmosphere may be relatively uniformly distributed at a mega-scale, the impacts of climate change differentially affect regions depending on their geographic location, ecological and economic conditions, prior preparation for extreme events, and past investments. The people most hurt by impacts may not have adequate representation at higher levels and may be unable to articulate clear solutions to reduce greenhouse gas emissions and help them adapt to the variety of threats they face (Agrawal, 2008).

Further, while many of the effects of climate change are global, the causes of climate change are the actions undertaken by individuals, families, firms, and actors at a much smaller scale. The familiar slogan "Think Globally but Act Locally” hits right at a major dilemma facing all inhabitants of our globe. To solve climate change in the long run, the day-to-day activities of individuals, families, firms, communities, and governments at multiple levels—particularly those in the more developed world—will need to change substantially. Many of those who need to change, however, have not yet accepted the reality of the threat and their need to act locally in a different manner. As Sovacool and Brown (2009a: 318) point out, "Individuals continue to drive 
alone, so much that single occupancy vehicle trips constitute more than 80 percent of all travel in the U.S. because people see it as more convenient than adjusting their schedules for mass transit or carpooling” (see also Burris and Lei, 2006). If families would change their fundamental behavior relating to how they insulate their housing and whether they buy fuel-efficient cars, however, these actions taken at a small scale would cumulatively reduce their greenhouse gas emissions and their energy consumption by around 30 percent (Vandenberg and Steinemann, 2007).

The problem of averting massive climate change—or a global "public bad"—would be a global “public good” (Sandler, 2004; Carraro, 2003). Millions of actors affect the global atmosphere. All benefit from reduced greenhouse gas emissions, but the problem is they benefit whether or not they pay any of the costs. In other words, beneficiaries cannot be excluded from the benefit of cleaner air. Trying to solve the problem of providing a public good is a classic collective action dilemma—and potentially the largest dilemma the world has ever knowingly faced.

The classic theory of collective action predicts that no one will change behavior and reduce their energy use unless an external authority imposes enforceable rules that change the incentives faced by those involved. This is why many analysts call for a change in institutions at the global level (see Stavins, 1997; Miller, 2004; Wiener, 2007). Given the presumption that any collective action problem that has global effects must be "solved" globally, several questions need to be addressed as analysts undertake the next round of research on climate change. They include the following:

1. Is the conventional theory of collective action the best theory for analyzing how to reduce the threats of massive climate change? 
2. If not, what key assumptions need to be changed related to (a) the basic theory and (b) potentially the assumptions made regarding the scale of effects produced by actions taken at less than global levels?

3. Are only global benefits generated from local efforts to reduce greenhouse gas emissions, or are there potential benefits at multiple scales?

4. Are actions being taken at less than global scale to reduce greenhouse gas emissions, or at least to offer some levels of adaptation?

5. Are large-scale governments usually better equipped to cope with collective action problems that have outcomes that are large scale themselves?

6. If multiple governments and other organizations work to reduce energy consumption and greenhouse gas emissions, does that only produce leakage, or chaotic systems, and potentially counterproductive processes?

7. How might a polycentric approach be an improvement over relying exclusively on a global approach to cope with global climate issues?

The paper is organized so as to address each of these questions in turn.

\section{The Conventional Theory of Collective Action}

The term "social dilemma" refers to settings where uncoordinated decisions motivated by the pursuit of individual benefits generate suboptimal payoffs for others and for self in the long run. Individual maximization of short-term benefits to self leads individuals to take actions that generate lower joint outcomes than could have been achieved. The reason that such situations are considered to be dilemmas is that at least one outcome yields higher returns for all who are involved, but participants posited as maximizing short-term material benefits make independent choices and are not predicted to achieve this outcome. The socially optimal outcome could be 
achieved if most of those involved "cooperated" by selecting strategies other than those prescribed by the Nash equilibrium. Since the suboptimal joint outcome is an equilibrium, however, no one is independently motivated to change their choice, given the predicted choices that others will make (Sandler, 1997, 2004; Sandler and Arce, 2003).

Social dilemmas thus involve a conflict between individual rationality and optimal outcomes for a group (Schelling, 1978; Lichbach, 1996; Vatn, 2005). Even if some individuals cooperate, others are predicted to "free ride" on the contributions of the cooperators. In addition to the assumption regarding the structure of payoffs leading to a deficient equilibrium, further assumptions made in most game theoretic models of social dilemmas include the following:

1. All participants have complete and common knowledge of the exogenously fixed structure of the situation and of the payoffs to be received by all individuals under all combinations of strategies.

2. Decisions about actions are made independently and simultaneously.

3. Participants do not communicate with one another.

4. No central authority is present to enforce agreements among participants about their choices.

When these assumptions are made for a game that is not repeated, or is finitely repeated, the theoretical prediction derived from noncooperative game theory is unambiguous—zero cooperation (Luce and Raiffa, 1957).

The structure of the tragedy of the commons as described by Hardin (1968) is consistent with that of a Prisoner's Dilemma. Game theory gave logical force to Hardin's expectation of noncooperation leading to socially suboptimal outcomes in the regulation of shared natural resources. Mancur Olson's major book, The Logic of Collective Action (1965), reinforced the 
link between Hardin's analysis of the tragedy of the commons and the game theoretic analysis of the Prisoner's Dilemma. Olson analyzed the problems facing citizens who might wish to achieve a public good through collective action. Olson's theory relates to the problem of overcoming social dilemmas in general. In Olson's analysis, collective action is a problem because the costs of contributing are concentrated while the benefits are diffused. The fundamental problem in both situations is the same: actions taken for individual benefit result in socially suboptimal outcomes. People who pursue individual self-interest are "free riders" in that they enjoy the benefit of others' restraint in using shared resources or others' contribution to collective action.

Olson's logic of collective action is important for the study of climate change as well as for the governance of natural resources and other questions of importance related to human relationships. Many objectives that individuals seek within a family, a neighborhood, a community, a region, a nation, or an alliance of nations may be produced by the actions of others — whether or not a particular actor contributes. If many individuals decide to "free ride" on the actions of others, the "others" may stop contributing to the collective good. If more and more actors pull out, eventually no one contributes. Basically, Olson laid out a theory of collective inaction. What might be of mutual benefit is not achieved. In the case of climate change, the joint "good” is reducing a joint "bad” caused by increased emissions of greenhouse gases. The joint goal is reducing the threats of massive climate change, of increased ocean levels, of increased variability in climate patterns, and many other global bads.

Without externally imposed regulations at the scale of the potential externalities, the theory predicts that the benefits that might be achieved through collective action are impossible to obtain. Under this view of the world, which became the "conventional" theory for many scholars interested in the sustainability of natural resources at multiple scales, little variance is 
predicted in the performance of groups jointly affected by their own actions. In the conventional theory, "self-organized groups" that have devised their own policies to achieve a public good or regulate a common-pool resource do not exist at any scale.

On the surface, the conventional theory of collective action appears to be precisely relevant to the analysis of climate change and other social dilemmas with global impacts. While individuals and organizations may not have complete information about the externalities they generate, it is reasonable to assume they have good information about their own immediate costs and benefits. Many of the decisions made that affect the release of greenhouse gases—how and with whom to travel to work and other destinations, the level of energy use, the type of investments in building infrastructure and new technologies for energy production—are made independently by multiple actors without communicating with others making similar decisions. And no central authority exists at the global level making authoritative decisions about payments for energy use and investments in new technologies—and enforcing these decisions.

The applicability of the conventional theory is considered to be so obvious by many scholars that few questions have been raised about whether this is the best theoretical foundation for making real progress toward substantially reducing greenhouse gas emissions and taking other actions to reduce the threat of massive harm brought about by climate change. Two broad grounds exist for doubting whether sole reliance on the conventional theory of collective action is a wise scientific strategy. The first is the weakness of empirical support for the conventional theory of collective action related to small- to medium-size environmental social dilemmas. The second is the existence of multiple externalities at small, medium, and large scales within the global externality that has been of primary concern in the academic and policy literature. The paper discusses each of these issues in turn. 


\section{The Lack of Empirical Support for the Conventional Theory of Collective Action}

In a major, book-length effort, Poteete, Janssen, and Ostrom (forthcoming) review the empirical support for the theory of collective action related to natural resource problems. They examine the evidence generated by in-depth case studies, meta-analyses of cases, large-scale comparative field studies, laboratory experiments, and agent-based models. The major finding is that the unambiguous predictions of the conventional theory are not supported. While many instances of free riding are observed in the array of empirical research, a surprisingly large number of individuals facing collective action problems do cooperate.

Contrary to the conventional theory, many groups in the field have self-organized to develop solutions to common-pool resource problems at a small to medium scale (Baland and Platteau, [1996] 2000; Agrawal, 2000, 2002; McKean, 2000; Wade, 1994; Schlager, 1994; Schlager et al., 1994; Ostrom, 1992, 2001; Ostrom et al., 1994; NRC, 1986, 2002; Dietz et al., 2003). Rational choice theory was used as a foundation for the conventional theory of collective action. Predictions from this theory are well supported when applied to the analysis of the provision and production of private goods in a highly competitive environment. Predictions from the theory are not well supported when applied to situations involving social dilemmas where participants trust one another to be effective reciprocators (Ostrom, 1998). Thus, before analyzing efforts to reduce the threat of massive costs related to climate change, it is essential to update the theory of collective action so that future policies are not made on the basis of a theory that appears to be so reasonable but has not received strong empirical support.

\section{Updating the Theory of Collective Action Related to Climate Change}

For future analyses of how individuals relate to natural resources at multiple scales, the conventional theory of collective action needs revision based on a behavioral theory of human 
action and a recognition of the importance of context in affecting levels of trust and reciprocity of those involved. Further, the application of this theory to climate change also needs to question whether smaller-scale externalities exist from the use of energy by individuals and firms and whether that may form a different foundation for future actions.

Since behavior in social dilemmas varies substantially across individuals as well as across settings, updated theoretical efforts depend on a behavioral theory of the individual (Camerer, 2003; Fehr and Gächter, 2000, 2002; Fehr and Leibbrandt, 2008; Fehr and Rockenbach, 2003) as well as on structural features of the particular dilemma that affect the likelihood of voluntary cooperation or relatively high levels of compliance with official rules. A behavioral theory of the individual assumes that while individuals do not possess perfect information, they are capable of learning more accurate information as they interact in a particular setting — especially when the rules enhance the accuracy and rapidity of feedback. It is appropriate to assume that individuals do seek benefits for self, but that individuals vary in their other-regarding preferences and norms about the appropriate actions they should take in particular settings (Sen, 1977; Frohlich and Oppenheimer, 1992; Cox et al., 2007; Crawford and Ostrom, 2005).

The capability of those involved to gain a reputation for being trustworthy and reciprocating the efforts of others to cooperate with their own cooperation turns out to be a central characteristic of settings where moderate to high levels of cooperation are sustained (Milinski et al., 2002; Rothstein, 2005; Poteete, Janssen, and Ostrom, forthcoming). To achieve its objects, any policy that tries to improve levels of collective action to overcome social dilemmas must enhance the level of trust by participants that others are complying with the policy or else many will seek ways of avoiding compliance. 
At scales less than the global commons, a core finding is that the features of an immediate micro-situation and the broader contextual setting in which individuals interact have a major impact on the likelihood of individuals acting cooperatively in collective action situations. Empirical studies focusing on common-pool resource dilemmas that are discussed and synthesized in Poteete, Janssen, and Ostrom (forthcoming) have identified a large number of variables that increase the likelihood of cooperation in social dilemmas. Among the most important are the following: (1) reliable information is available about the immediate and longterm costs and benefits of actions; (2) the individuals involved see the common resource as important for their own achievements and have a long-term time horizon; (3) gaining a reputation for being a trustworthy reciprocator is important to those involved; (4) individuals can communicate with at least some of the others involved; (5) informal monitoring and sanctioning is feasible and considered appropriate; and (6) social capital and leadership exist, related to previous successes in solving joint problems. Further, when individuals and groups face rules and sanctions imposed by external authorities, these are viewed as legitimate and enforced equitably on all.

Thus the updated theory of collective action developed in Poteete, Janssen, and Ostrom (forthcoming) is not as pessimistic about the likelihood of diverse organizations at multiple levels finding policies that increase levels of voluntary cooperation or increase compliance with rules established by governmental authorities. Instead of presuming that cooperation related to social dilemmas is an impossibility, the presumption should be that cooperation will occur in settings with several broad characteristics. These include the following:

1. Many of those affected have agreed on the need for changes in behavior and see themselves as jointly sharing responsibility for future outcomes. 
2. The reliability and frequency of information about the phenomena of concern are relatively high.

3. Participants know who else has agreed to change behavior and that their conformance is being monitored.

4. Communication occurs among at least subsets of participants.

The exact structure cannot be worked out at a general level, as many specific features of a particular dilemma affect what has a chance of working. The crucial factor is that a combination of structural features leads many of those affected to trust one another and to be willing to do an agreed-upon action that adds to their own short-term costs because they do see a long-term benefit for themselves and others and they believe that most others are complying.

The problem of collective action does not disappear once a policy to deal with an externality is made by a government. Even governmental policies need to rely to a great extent on willing cooperation by citizens. When citizens approve of a governmental policy, think they should comply, and this view is complemented by a sense that the governmental policy is effectively and fairly enforced, the costs of that enforcement are much lower than when citizens try to evade the policy. Trust that governmental officials are objective, effective, and fair is more important in enabling a governmental policy to work than reliance on force (Rothstein, 1998, 2005).

It is obviously much easier to craft solutions for collective action problems related to smaller-scale common-pool resources than for the global commons. Many of the policy analyses recommending "solutions" at an international level to be implemented by national governments are based on a fear that unless global solutions are made for global problems, these problems will continue unabated. The third major question addressed above was, Are only global benefits 
generated from local-level efforts to reduce greenhouse gas emissions, or are there potential benefits at multiple scales? If there are benefits at multiple scales, as well as costs at these scales, applying the updated theory of collective action needs to take these into account for analyzing proposed solutions to climate change.

\section{Are Only Global Benefits Generated from Reducing Greenhouse Gases Emissions?}

Greenhouse gas emissions are the result of an extraordinarily large number of actions taken at multiple scales. As mentioned above, decisions within a family as to what form of transportation to use for various purposes, what car to purchase, and what investments to make for power consumption within the home all have small effects on the global atmosphere. Similar decisions within firms are also important, as buildings in general account for "more than 70 percent of the electricity use and almost 40 percent of greenhouse gas emissions in the United States” (Fuller et al., 2009, citing several U.S. Department of Energy reports). Proposals for substantial increases in energy taxes at a national level (to comply with proposed international agreements) are strongly urged as the only way of changing the decisions of individuals and families, as they make decisions based on individual and family household budgets and do not take the external costs they generate into account.

Without shared knowledge about the external costs of these actions, shifts in preference functions to take into account benefits for others, and reduced discount rates, no change at a small scale can be expected. As the scientific community has achieved a higher level of agreement about human impacts on the global atmosphere, knowledge of the effects of individual and family actions is becoming more and more available. Discussions within the family and with neighbors in a community about actions that can be taken locally to reduce greenhouse gas emissions are also important factors leading to the potential for change. Local 
discussions and meetings generate information about the prevailing unrecognized costs of individual and family activities as well as sometimes leading to a change in the preferences of individuals involved. Even without major taxes imposed on energy at a national level, however, families that decide to invest in better insulation and more efficient furnaces and other appliances, to join a carpool whenever feasible, and to take other energy-conserving actions can save funds over the long run. They may face high up-front investments to achieve some of these benefits, but there are potential benefits to be achieved even at a household level.

Communities that have established power networks that enable households to invest in solar power that is used for household energy use and when not needed is contributed to the network, can potentially reduce local energy costs as well as reducing greenhouse gas emissions. Investments in better waste disposal facilities also generate local benefits as well as helping on global emissions. Efforts to reduce pollution levels in large metropolitan areas focus both on total energy use and on emissions of particulates and thus generate benefits at a metropolitan level as well as globally. Decisions to reduce subsidies to various types of economic development that increase emissions are difficult for any government to make, but some of these decisions can reduce the administrative costs of government as well as improving the environment.

Efforts at a local level are challenging. The Cities for Climate Protection (CCP) campaign (sponsored by the International Council for Local Environmental Initiatives) tried to encourage cities to find ways of controlling greenhouse gas emissions but found it a difficult task. Part of the problem is that "the problem" has been framed so often as a global issue that local politicians and citizens sometimes cannot see that there are things that can be done at a local level that are important steps in the right direction (Betsill, 2001). Further, some claims of achievements have 
been questioned by analysts who have dug into the reports (Eadson, 2008). Given that many of the actions generating greenhouse gas emissions are taken at multiple scales, activities could be organized at multiple scales, ranging from households, farms, and cities at a local scale to regions within a state, states, regional units that cross state boundaries and the globe (Kates and Wilbanks, 2003).

\section{What Efforts to Reduce Greenhouse Gas Emissions Are Being Taken}

\section{at Less Than a Global Scale?}

It is not possible to do a full inventory in this paper of all of the projects going on across the world at multiple scales. What I can do is focus on some of the projects that have been organized at a local level, at the level of state governments in the United States, and at a regional level in Europe, and discuss some of the efforts to reduce emissions substantially.

\section{Local-Level Projects and Alliances to Reduce Local-Level Externalities}

One of the most successful efforts made by many local governments across the United States has been to reduce the level of fine-particulate air pollution (which in some cases has reduced greenhouse gas emissions as well). Pope et al. (2009) have just completed a major study of the impact on life expectancy of particulate matter in the air sampled over the period from 1979 to 2000 for 51 metropolitan areas (including more than 200 counties). ${ }^{1}$ Metropolitan areas across the nation have reduced air pollution levels by one-third. Pope et al. also found that increased life expectancy during this period was associated with reductions in fine-particulate air pollution

1. This study also illustrates the importance of effective monitoring efforts. The U.S. Environmental Protection Agency (EPA) maintained the Inhalable Particle Monitoring Network from 1979 to 1983 for 61 metropolitan areas. The monitoring effort was not continued until the passing of the National Ambient Air Quality Standards for Particle Pollution in 1997. EPA then developed the Aerometric Information Retrieval System, which has continued the monitoring process. The maintenance of reliable, comparative information over time is a very important step in coping with large-scale externalities, both to assess who is complying with policies and to compare the effectiveness of diverse strategies in different units. 
after controlling for socioeconomic, demographic, and other variables associated with life expectancy. Their statistical analysis shows that the gain in average life expectancy that could be attributed to reduction in air pollutants was one-third of a year.

Retrofitting buildings to add insulation, solar photovoltaics, and more efficient heating systems is one strategy that can be pursued at a local level and may generate long-term energy cost savings for the firm or family that takes such actions as well as reducing greenhouse gas emissions. The up-front costs of such efforts are frequently daunting, however, even when the private investment will reduce private costs over the long run. By a public ballot approved by 81 percent of the voters, Berkeley, California, has adopted a general policy to reduce emissions substantially over time. One of the programs is called Berkeley FIRST (Financing Initiative for Renewable and Solar Technology) and is designed to reduce the barrier of up-front costs. To participate in the program, the owner of a commercial or residential building asks a contractor for an estimate of the costs of new solar energy equipment or energy-efficiency improvements to the building that would likely cost between $\$ 4,000$ and $\$ 20,000$ (Pope et al., 2009). The owner then submits an application to the city, and staff review the estimate and ensure that the owner has clear title.

After the municipality approves the application, the work is completed, a lien is placed on the property, and a check is issued to the property owner. A special tax is added to future property bills. If the property is sold before the end of the 20-year repayment period, the new owner pays the remaining special taxes as part of their property's annual tax bill. The interest component of the special tax payments will be tax deductible, similar to a home equity line or home mortgage....

The City of Berkeley started accepting applications through its Web site on 5 November 2008, and applications to claim \$1.5 million available for the pilot were submitted within 10 minutes. (Pope et al., 2009: 25) 
Obviously the demand for making these investments in improving buildings so as to reduce energy consumption is very high. The City of Berkeley plans to increase the funds available to support this program over time.

Other cities have started a variety of "green” initiatives that are prominently displayed on their home pages on the Web. The City of Toronto, for example, has set up an "environmental portal” that announces more than a dozen current city policies, related publications, and meetings that are focused on climate change. ${ }^{2}$ In 2008 , the city allocated $\$ 700,000$ to renewable energy projects combining major investments averaging around $\$ 100,000$ each for building rooftop gardens, solar photovoltaic panels on houses, and solar water heating systems, and a dozen smaller projects ranging around $\$ 25,000$ to support neighborhood efforts to enhance the forested areas of local parks and gardens and for local-level organizations working with communities to hold planning meetings to think through better bicycle paths and other activities that can be undertaken at a small, neighborhood scale. The City of Toronto has increased the budget for its “Live Green Toronto” program to \$2.2 million for 2009.

Mayors of large cities are also banding together to discuss actions to reduce carbon emissions that can be taken locally but that if taken jointly can have a much bigger effect. In October 2005, 18 large cities sent representatives to London to examine actions that could be taken at a municipal level; to reexamine urban policies that could be revised, including their own purchasing policies; and to discuss ways of encouraging more investment in climate-friendly technologies in their cities. The mayors reviewed the results of the $£ 8$ congestion charge imposed by London on vehicles that drive within the city's central zone during business hours, from 7

2. http://www.toronto.ca/environment/index.htm (accessed February 9, 2009). 
a.m. to 6 p.m. ${ }^{3}$ In October 2008, a merger with the Clinton Climate Initiative was arranged to create the C40 Cities Climate Leadership group, whose members have jointly pledged to reduce emissions in each of their cities to meet or even improve on Kyoto standards. The C40 Large Cities Climate Summit was held in May 2007 to exchange information about many policies adopted to reduce emissions and to announce a \$5 billion global Energy Efficiency Building Retrofit Program by the Clinton Climate Initiative. ${ }^{4}$ A similar league, the World Mayors Council on Climate Change, was initiated by the mayor of the City of Kyoto (Japan) in December 2005, soon after the Kyoto Protocol entered into force. Currently there are 20 members of this alliance, from all regions of the world.

Other local-level efforts to overtly increase the level of alternative energy production or reduce the level of automobile use have been reported for many cities around the worldincluding Sorsogon, Philippines; Esmeraldas, Ecuador; Maputo, Mozambique; and Kampala, Uganda, where efforts are supported by the Cities in Climate Change Initiative, funded by the government of Norway and the UN Development Account (UN-Habitat, 2008).

A complete inventory cannot be undertaken in this paper, though it would be a good subject for a future research project. But the major point is that many local governments and community organizations have recognized that actions undertaken at a local level are a major source of carbon emissions and that a need exists to tackle these at the local level as well as at higher scales.

3. A Wikipedia article on the London Congestion Charge (accessed February 9, 2009) reports that between 2003 and 2006 the $\mathrm{CO}_{2}$ level in the city fell by 20 percent as a result of reduced traffic levels, better traffic flow, and improved vehicle technology. The speed of traffic flow and the reliability of bus schedules have also been improved.

4. http://www.c40cities.org/ (accessed February 1, 2009). 


\section{State-Level Projects in the United States}

The State of California not only is the 12th largest emitter of greenhouse gases in the worldwith emissions comparable to Australia's — but is also now one of the leading states in adopting policies related to climate change (Engel, 2006). For example, in 2006, the California legislature passed the Global Warming Solutions Act, aimed at reducing greenhouse gas emissions in the state by 25 percent by 2020 by requiring drastic reductions in major industries, including oil and gas refineries and utilities. ${ }^{5}$ The California Air Resources Board is charged with developing a market-based, cap-and-trade program to implement the required reductions.

The Colorado legislature passed State House Bill 08-1350, signed into law in 2008, to enable local governments within the state to adopt policies similar to the Berkeley FIRST program. The legislation allows municipalities in Colorado to finance approved building improvements and enables property owners to pay off capital investments made to decrease their use of fossil fuels for heating and electricity through repayments over 20 years. In July 2007, Florida Governor Charlie Crist brought together government, business, and scientific leaders from across the state to discuss what actions could be taken by Florida to address climate change issues. At the conclusion of the meeting, several executive orders were signed to set out targets for reducing greenhouse gas emissions in Florida and to change the building code to require increased energy efficiency in new construction. ${ }^{6}$

Efforts are also being made among the states to develop joint policies. The Regional Greenhouse Gas Initiative (RGGI), joined by 10 states in the Northeast and Mid-Atlantic regions of the United States, plans to reduce $\mathrm{CO}_{2}$ emissions from the power sector by 10 percent by

5. Global Warming Solutions Act of 2006, Calif. Assembly Bill 32.

6. http://www.dep.state.fl.us/climatechange/ (accessed June 27, 2008). 
2018. ${ }^{7}$ Further, RGGI is one of the first market-based efforts in the United States aimed at reducing greenhouse gas emissions by auctioning emission allowances and investing the proceeds in clean energy technologies and the creation of green jobs in each of the states. The third auction occurred on March 18, 2009. ${ }^{8}$

\section{European Efforts}

In Europe, interventions tend to combine local, national, and regional levels. The EU Emissions Trading Scheme (EU-ETS) was developed so as to reduce the economic costs of meeting the European Union's Kyoto target of 8 percent $\mathrm{CO}_{2}$ reduction by 2012. The scheme includes around 10,000 large industrial plants in the power generation, iron and steel, glass, brick, and pottery industries, but not the transport sector. Operators of these facilities receive emission allowances that are good for a one-year period. If an allowance is not fully used by the assigned operator (after verification), the unused portion may be sold to other facilities that cannot yet meet their assigned target. The official data issued by the European Environmental Agency (EEA) in 2006 show that the EU members that had signed the Kyoto Agreement were able to achieve in 2005 a 2 percent cut in $\mathrm{CO}_{2}$ emissions compared with 1990 levels and that greenhouse gas emissions were projected to decline further by 2010 compared with 2004 levels (EEA, 2006: sections 8 and 9).

While a considerable accomplishment has been achieved, some concerns have been raised — which could also be raised regarding the RGGI approach in the United States—-that some energy-intensive sectors may relocate to regions that have less stringent policies on climate change or none at all.

7. http://rggi.org/home/ (accessed February 7, 2009).

8. http://www.climatetrust.org/solicitations_RGGI.php. 
To the extent this happens, the EU-ETS program will be responsible for shifting production to countries that allow a free-for-all with emissions. The risk of carbon leakage is said to be high, for example, for the European chemical and lime industries. The chemical industry is highly energy intensive and competes in a global market where it is not possible to pass on unilateral costs, conditions that are ripe for carbon leakage. . . . Carbon leakage is a risk because of high production costs within the EU including $\mathrm{CO}_{2}$ costs compared with lower costs of products imported from outside the EU which include transportation costs but no $\mathrm{CO}_{2}$ costs. (Sovacool and Brown, 2009b: 324)

We return to the potential problems of leakage associated with less than global efforts to avert massive climate change in the section below that discusses the problems and possibilities of organizing efforts to cope with climate change at diverse levels.

\section{Are Large-Scale Governments Usually Better Able to Cope with Collective Action?}

While the presumption is made in many policy discussions that global solutions are necessary for coping with the problems of climate change because of the inadequacy of local and regional efforts, few of these analyses examine the problems that large-scale units may face in developing effective policies related to resources. Before making a commitment that the global level is the only scale on which to address climate change, one should at least reflect on past efforts to adopt uniform policies by very large entities, efforts intended to correct for problems of collective action. The presumption that locals cannot take care of public sector problems has led to diverse policies to place responsibility for local public services on units of government that are very large, frequently lacking the resources to carry out their assignments, and overwhelmed with what they are assigned to do.

Contemporary assignments to regional, national, or international governments of the exclusive responsibility for providing local public goods and common-pool resources remove authority from local officials and citizens to solve local problems that differ from one location to the next. Doug Wilson, Research Director for the Institute for Fisheries Management and Coastal 
Community Development in Denmark, has recently reflected on the evolution of fisheries policies in the European Union. ${ }^{9}$

The Common Fisheries Policy (CFP) as it is called is an "exclusive competence" of the European Union (EU), meaning that all decisions are taken at the level of the Union. . . .

The CFP is not only politically important within the overall effort to build a new kind of polity in Europe; it is also failing to do a very good job of maintaining sustainable fish stocks. Fisheries scientists tell us that, in 2003, 22\% of the fish caught from stocks managed by the CFP were taken from stocks that were smaller than they should have been for sustainable fishing. Neither scientists, fishers, government agencies, nor marine conservation groups are happy with the CFP, and there are myriad attempts to reform it. The reforms include better policy, better data gathering, a reduction in perverse subsidies to the fishing industry and, finally, 30 years after most other fisheries management agencies had moved beyond topdown management, some serious attempts at stakeholder involvement. (Wilson 2006: 7)

Other fisheries-related policies adopted by large-scale units have also exhibited major problems. ${ }^{10}$ The United Nations Conference on the Law of the Sea allocated about one-third of what had been considered international ocean to individual nations because of the inability of international authorities to regulate ocean fisheries effectively (United Nations, 1982). Exclusive Economic Zones (EEZs) were created that extend 200 nautical miles along the borders between the ocean and coastal states and extended full sovereign powers to these states to manage coastal fisheries so that they are not overexploited. Instead of reducing overharvesting, however, many national governments subsidized expansions of fishing fleets that increased the demand on coastal fisheries and placed more fishing areas in danger of overexploitation (Walters, 1986). The models of fishery dynamics used by national governments tended to be relatively crude and led to inaccurate assessment of fishery stocks (Wilson, 2002).

9. Emphasis on top-down planning is certainly not the way that Europe developed. Since the 11th century, thousands of independent water boards were established in the delta of the Rhine River with their own rules and physical structures. These water boards drained the swampy land and protected the land from being inundated except during extreme storms (Toonen 1996; Andersen 2001). In Switzerland, alpine peasants devised a variety of private and common-property systems to earn income from a diverse ecology (Netting 1981). More than 1,000 free cities with their own charters and legal traditions flourished in Europe during the Middle Ages and were the foundation for modern constitutional democracies (Berman 1983).

10. See Clark (2006) for a review of fisheries-related policies adopted by national governments that initially led to perverse outcomes_-some of which were eventually reversed. 
The Department of Fisheries and Oceans in Canada, for example, developed a model of stock regeneration for northern cod that scientists later found to be flawed (Harris, 1990). Local cod fishers in Newfoundland raised serious questions in the late 1980s and predicted a near-term collapse, but the Canadian government refused to listen and assured doubters that its model was correct. In 1992, however, the cod stock collapsed and the Canadian government declared a moratorium on all fishing in Canadian waters. This has generated very substantial costs for local fishing villages dependent upon that stock, which they had earlier managed relatively effectively (Finlayson, 1994; Finlayson and McCay, 1998).

The capability of other large governmental bodies to make scientifically recommended policies related to fishing quotas has also been questioned. The European Union established a 2007 Fishing Quota for the eastern Baltic cod, but ignored the warning issued by the International Council for the Exploitation of the Seas (ICES). ICES had urged the European Union to skip a full year before authorizing any catch (Burton, 2006). Thus the faith in the capability of very large-scale units to make better scientific judgments and implement them is not fully realized in regard to ocean fisheries, which, while not global in scope, are larger than most territorially based resources.

Problems have also been noted in the way the Clean Development Mechanism (CDM) authorized by the Kyoto Protocol is being implemented. Several CDM processes are involved. One CDM process is supposed to replace carbon-emitting energy production processes with "green energy production.”

This process works approximately in this fashion: A developing country decides to forgo the construction of a power plant using coal as the energy source and emitting substantial greenhouse gases as a result. It plans to build a wind farm that is more "carbon friendly." The 
country applies for credit in the form of Certified Emissions Reductions (CERs) that it can sell to industrialized nations wishing to buy CERs as authorized by the Kyoto Protocol (Lohmann, 2008). The income from selling the CERs can then, in principle, be allocated to the construction of the wind farm, which is more expensive as well as being carbon neutral.

The problem with this highly complemented and flexible system is that it can be gamed (Sovacool and Brown, 2009). Only 300 of the thousands of CDM projects that are under way have received accreditation by the United Nations. As it turns out, a large proportion of the CERs relate to trifluoromethane, HFC-23, a greenhouse gas that is not associated with transportation or power generation but is used as a refrigerant—and is a highly profitable greenhouse gas to claim to have “averted.” As Sovacool and Brown (2009) conclude, the CDM has unfortunately made HFC-23 abatement too profitable.

The sale of carbon credits generated from CERs for HFC-23 has become far more valuable than its production in the first place. Manufacturers of HFC-23, responding to market demand for CERs, started producing it just to offset it. Researchers at Stanford University have calculated that, at a result, payments to refrigerant manufacturers and carbon market investors to governments and compliance buyers for HFC-23 credits have exceeded $€ 4.7$ billion when the costs of merely abating HFC-23 would have been about $€ 100$ million —a major distortion of the market. (Sovacool and Brown, 2009: 14, citing Wara, 2007; and Wara and Victor, 2008)

Other CDM processes relate to efforts to decrease carbon emissions as a result of deforestation. But what exactly is deforestation? In the American West the kind of fire that counts as "deforestation" is subject to considerable debate among public officials. Small fires may help prevent very large-scale forest fires in regions where the forest ecology has developed in a high-frequency, low-severity fire regime (Covington, 2000; Fule et al., 2004; Odion and Hanson, 2006). 
The California Climate Action Registry, ${ }^{11}$ for example, considers all thinning of forests to send carbon to the atmosphere even though thinning reduces the risk of an even greater fire burning down an entire stand. "If, by contrast, that same forest is not thinned and instead experiences a catastrophic fire, the $\mathrm{C}$ stock baseline is simply reduced, as if no $\mathrm{CO}_{2}$ emissions had occurred during the fire” (Hurteau et al., 2008). Scientists criticize the carbon accounting methodology as a "one size fits all" policy that does not account for the diversity of ecosystems involved and may penalize actions that help restore forest ecosystems rather than destroy them (ibid.). As Boyd (2009: 3) reflects, "solving problems through centralized controls and global blue prints tends to create its own vulnerabilities in the long term.”

Since the Bali round of negotiations held in December 2007, efforts to reduce emissions from deforestation and degradation (REDD) have been added to the portfolio of activities authorized under the Kyoto Protocol. It is undoubtedly very important to recognize that forest ecosystems store an immense quantity of carbon and that harvesting timber and converting forests to other uses is as important a source of greenhouse gas emissions as power production. Thus the scientific foundation for adopting REDD is quite strong. Designing REDD projects so that new projects do not just lead to further leakage is a substantial problem. Further, ensuring that the rights of indigenous people are at least protected, and ideally enhanced, as a result of support of their management of forest ecologies is a goal that is widely shared by social activists at multiple scales. Accomplishing this goal while expanding the amount of forested land in developing countries would be economically efficient but a difficult challenge. ${ }^{12}$ Currently there

11. California Climate Action Registry, Forest Sector Protocol (2007), http://www.climateregistry.org/PROTOCOLS (accessed January 15, 2009).

12. John Vidal, in an article in The Guardian (October 17, 2008), stressed that recognizing forest community rights would be a more cost-effective mechanism for reducing emissions than paying organizations to plant trees. "A study by Jeffrey Hatcher, an analyst with Rights and Resources in Washington, found that it costs about $\$ 3.50$ (€2) per 
is considerable debate about this program, and too few projects have been adopted to make a serious evaluation of the possibilities and threats (see O'Sullivan, 2008 and other chapters in Streck et al., 2008; and Corbera and Brown, 2008).

The description in this section of problematic policies of large-scale governmental units related to climate change and other environmental issues is not meant to challenge the need for global policies related to climate change. The intent is to balance the major attention that has been given in the policy literature to the need for global solutions as the primary strategy for coping with climate change. Many criticisms have been made of policies adopted by smallerscale private and governmental units as evidence that we must go global. Yet extensive research on institutions related to environmental policies has repeatedly shown that creative, effective, and efficient policies, as well as disasters, have been implemented at all scales. Dealing with the complexity of environmental problems can lead to "negative learning” by scientists and policy makers at all scales (Oppenheimer et al., 2008). Reliance on a single "solution" may be more of a problem than a solution (Pritchett and Woolcock, 2003). It is important that we recognize that devising policies related to complex environmental processes is a grand challenge and that reliance on one scale to solve these problems is naïve.

\section{Are There Too Many Actors Working on Climate Change?}

One of the criticisms leveled at current efforts to reduce greenhouse gas emissions is that too many projects and activities are operating at multiple scales and that the system is chaotic. Unquestionably, many problems characterize the current efforts and many of these do relate to the lack of effective policies at an international level. Further, some of the projects that are overtly aimed at reducing greenhouse gas emissions may well be ineffective, too costly, and 
rewarding actors who are not genuinely interested in reducing the threat of climate change but are instead looking for opportunities to gain funds and search for minimal ways of meeting project objectives .

Overall, however, massive disagreements exist about how to achieve a global solution between those who urge a "cap and trade” approach and those who wish to see taxes placed on emissions. Further disagreements exist about how to allocate funds that are derived from largescale policies. The likelihood of developing an effective, efficient, and fair system to reduce greenhouse gas emissions that can be rapidly initiated at the global level appears to be very low. Given the severity of the threat, simply waiting for resolution of these issues at a global level, without trying out policies at multiple scales because they lack a global scale, is not a reasonable stance.

As discussed above, the benefits from reduced greenhouse gas emissions are not just global in scope. The benefits are distributed across scales-from the household to the globe. Thus, because units smaller than the globe have sought to reduce emissions, at least some marginal reduction of greenhouse gas emissions is likely to result from projects undertaken at multiple scales while waiting for global policies to evolve. Doing nothing simply means increasing the level of greenhouse gases, emitted at an ever greater rate. While not yet the amount of reductions that climate scientists estimate is needed to avert calamity, reduction levels do appear to be growing in at least some parts of the world, which may provide examples to other regions of what can be done and what these actions cost. And better technologies for tracking $\mathrm{CO}_{2}$ emissions are being developed (Normille, 2009) that will help evaluate the effectiveness of all policies in the future. 
Currently, it is important that we examine some of the key problems that have been identified as plaguing efforts to control greenhouse gas emissions. Recognition of problems is essential to start serious efforts to find methods to reduce them. The problems raised most frequently are leakage, inconsistent policies, free riding, and inadequate certification.

\section{Leakage}

One of the problems frequently identified with subnational projects aimed at reducing carbon emissions is leakage. Two types of leakage can occur from policies adopted at less than global scale: leakage between locations and market leakage (Ebeling, 2008: 49-51). Leakage between locations occurs when an activity that would have taken place in X location is shifted to $\mathrm{Y}$ location because of a climate change project that occurs in X location. As discussed above, the EU efforts to reduce emissions from industrial producers may, in some cases, simply shift the emissions that would have been produced by a European chemical firm to another location in a developing country. There, the costs of production may be lower, but carbon is still emitted in the production of chemicals and in the transportation of the chemicals to European locations (Chomitz, 2002). Similarly, farmers who are forced to leave a location because of a REDD project of planting trees may simply move to a new location and cut down the timber located there unless there are commitments that they must make related to funds they obtain and their activities are monitored for several years after the project is started.

Market leakage refers to changes in price structure that may occur as a result of restrictions placed on harvesting from forests. Such restrictions reduce the volume of timber and other forest products generated in one area. This stimulates an increase in the prices of these products. If everything goes well, higher prices encourage the intensification of agricultural and forest production in other areas, and they do not stimulate more deforestation. "In a less 
favorable scenario, particularly when land-use regulations are poorly enforced, higher prices provide an additional incentive to clear forests for timber or agriculture elsewhere, thereby reducing the net benefits of the climate mitigation project” (Ebeling, 2008: 50).

\section{Inconsistent Policies}

Closely related to the problem of leakage is the problem of inconsistent policies. Industrial firms that are trying to develop new technologies to reduce greenhouse gas emissions may find it costly when policies vary in different regions. Potential sales of new technology are limited to areas where the technology fits the policies adopted, and these areas may not be large enough to generate sales warranting the investment in new technology.

\section{Free Riding}

Whenever actions taken by some individuals or organizations benefit a larger group, a risk always exists that some participants will free ride on the efforts of others and not contribute at all or not contribute an appropriate share. Currently, there are many governmental and private entities at multiple scales that are increasing their greenhouse gas emissions substantiallyespecially in the developing world—without adopting any policies to reduce emissions. This is a major problem. And current debates over who caused the great increase in the presence of greenhouse gases in the atmosphere in the first place and thus who should be paying the most in

the future are legitimate debates at the same time that they may cover up a free-riding strategy by at least some of those involved.

\section{Inadequate Certification}

For policies adopted at any scale that provide diverse rewards for projects that reduce greenhouse gas emissions, there is a need for skilled personnel to certify that a project does indeed reduce 
ambient $\mathrm{CO}_{2}$ by some specified amount over a defined time period. A very active new industry of "global consultants" has emerged. While many consultants do have good scientific training, the greatly increased need for certification has generated opportunities for at least some contractors lacking appropriate skills to earn money in the new "certification game.” Sovacool and Brown (2009: 14) report on one study that evaluated 93 randomly chosen CDM projects and "found that in a majority of cases the consultants hired to validate CERs did not possess the requisite knowledge needed to approve projects, were overworked, did not follow instructions, and spent only a few hours evaluating each case.”

\section{What Are We Learning?}

Debating whether local and national efforts to reduce greenhouse gas emissions undermine global efforts or whether global efforts generate net costs rather than net benefits produces a lot of hot air but not necessarily better solutions. It is essential that we recognize (1) the complexity of causes of climate change, (2) the challenge of acquiring knowledge about causes and effects in a world that is changing rapidly, (3) the wide diversity of policies that can lead to reduced emissions but might also enable opportunistic efforts to obtain a flow of funds by appearing to reduce emissions while not having a real impact or, worse, effectively increasing rather than decreasing emissions, (4) the opportunities that major sources of funding open up for policy experiments if funds are also allocated to monitoring and evaluation of the benefits and costs of the experiments, and (5) that all policies adopted at any scale can generate errors, but that without trial and error, learning cannot occur.

Acknowledging the complexity of the problem, as well as the relatively recent agreement among scientists about the human causes of climate change, leads to recognition that waiting for effective policies to be established at the global level is unreasonable. Rather than only a global 
effort, it would be better to self-consciously adopt a polycentric approach to the problem of climate change in order to gain the benefits at multiple scales as well as to encourage experimentation and learning from diverse policies adopted at multiple scales. Let us turn to a discussion of what a polycentric approach means.

\section{A Polycentric Approach to the Problem}

The title of this paper is “A Polycentric Approach for Coping with Climate Change.” I purposely chose the term "polycentric" for the title even though it has not previously been applied to the analysis of climate change. Colleagues associated with the Workshop in Political Theory and Policy Analysis at Indiana University have developed this approach over the years for the analysis of collective action problems in urban areas that are characterized by diverse public goods and services best provided at multiple scales. Given that multiple benefits at diverse scales are generated from efforts taken to reduce greenhouse gas emissions, as discussed above, I thought it would be a useful approach to take with respect to global change. Let us briefly review the origin of the term.

During the 1950s, massive criticism was leveled at metropolitan areas across the United States and Europe because of the large number of small-, medium-, and large-scale governmental units operating at the same time. Scholars thought this was chaotic. Vincent Ostrom, Charles Tiebout, and Robert Warren wrote a classic article in 1961 entitled "The Organization of Government in Metropolitan Areas: A Theoretical Inquiry.” The authors were trying to make scholars aware that a simple dichotomy between "the" market and "the" government was not a good scientific approach to the study of public economies. Further, "the” market is usually composed of many small-, medium-, and large-scale firms, and the expected efficiency of a market disappears if it is consolidated into a monopoly. 
There is a lot to learn from economics about the dangers of allocating all capabilities to a single unit, even though one cannot apply all lessons derived from the analysis of market economies to the public sector. Drawing on the rich tradition of public sector development in the United States, the authors urged readers to think of the public sector as a polycentric system rather than a monocentric hierarchy. In a later essay, Vincent Ostrom (1999: 57) defined a polycentric order as "one where many elements are capable of making mutual adjustments for ordering their relationships with one another within a general system of rules where each element acts with independence of other elements.” Opening up the discourse about the public sector enables one to analyze and measure how systems with diverse structures perform in the provision and production of different types of public goods.

The early theoretical work on polycentricity stimulated three decades of very intense research on governance of one of the major public goods for urban areas - that of providing public safety across a metropolitan region. Since these findings are not well known by scholars focusing on global change questions, a brief summary of the findings from this research program, as well as more recent studies of public education, is presented in appendix A. In addition to the specific findings about the efficiency and effectiveness of diverse scales of provision of urban public goods presented in appendix A, it is also useful to review the basic assumptions of a polycentric approach as applied to the study of urban areas. These are as follows:

1. Public goods and services differ substantially in regard to their production functions and their scale of effects.

2. Policy preferences tend to be more homogeneous within smaller units than across an entire metropolitan area. 
3 Citizens who live in areas served by multiple jurisdictions learn more about the performance of any one jurisdiction by seeing or hearing about how problems are handled in other jurisdictions.

4. The presence of large numbers of potential producers of urban goods and services in a metropolitan area allows elected officials more effective choice of producers.

5. Multiple jurisdictions with different scopes and scales of organization allow citizens and officials more choice in selecting modes of providing and producing public goods to try to utilize the best available technology, to achieve economies and avoid diseconomies of scale, and improve performance over time.

6. Producers who must compete for contracts are more likely to search for innovative technologies, to encourage effective team production, as well as citizen coproduction, so as to enhance their own performance (V. Ostrom, 2008a, 2008b; E. Ostrom, Parks, and Whitaker 1978).

Polycentric metropolitan regions tend to reduce opportunistic behavior even though no institutional arrangement can totally eliminate opportunism with respect to the provision and production of collective goods. Allowing citizens to form smaller-scale collective consumption units encourages face-to-face discussion and the achievement of common understanding. Creating larger collective consumption units reduces the strategic behavior of the wealthy trying to escape into tax havens where they could free ride on the tax contributions of citizens in other jurisdictions. Larger units also can more effectively cope with urban goods and services that have large-scale effects and real economies of scale.

Some readers of this paper will ask, What is the relevance of the polycentric approach for the analysis of global public goods? The initial relevance of the polycentric approach is the 
parallel between the earlier theoretical presumption that only the largest scale was relevant for the provision and production of public goods for metropolitan areas, and the contemporary presumption that only one scale is relevant for policies related to global public goods. Extensive empirical research found, however, that while large-scale units were part of effective governance of metropolitan areas, small and medium-scale units were also necessary components. An important lesson is that simply recommending a single governmental unit to solve global collective action problems—-because of global impacts—needs to be seriously rethought and the important role of smaller-scale effects recognized.

As discussed above, instead of the benefits derived from reducing greenhouse gases existing only at the global level, multiple benefits are created by diverse actions at multiple scales. Potential benefits are even generated at a household level. Better health is achieved by members of a household who bike to work rather than driving. Expenditures on heating and electricity may be reduced when investments are made in better construction of buildings, reconstruction of existing buildings, installation of solar panels, and many other efforts that families as well as private firms can make that pay off in the long run.

Further, the extensive empirical research on collective action discussed above has repeatedly identified a necessary central core of trust and reciprocity among those involved that is associated with successful levels of collective action. If the only policy related to climate change was adopted at the global scale, it would be particularly difficult to increase the trust that citizens and firms need to have that other citizens and firms located halfway around the globe are taking actions similar to those being taken "at home.” When participants fear they are being "suckers" for taking costly actions while others free ride, more substantial effort is devoted to 
finding deceptive ways of appearing to reduce emissions while not doing so. A key problem is monitoring.

\section{Diverse Monitoring Strategies}

Relying only on preexisting levels of trust and reciprocity among those involved in collective action is not associated with long-term success. This is especially the case when new problems arise that groups have not previously faced. Rules must be enforced in some manner to achieve sustainable systems, but the question of how rules will actually be enforced is frequently ignored when a reform is proposed. Our current research on resource regimes is highly relevant (Gibson et al., 2000; Ostrom and Nagendra, 2006). In efforts to enhance another large-scale collective good—biodiversity—all too many “comanaged paper parks” have been drafted in the home office of an overseas donor or even in a country's capital city only to be destroyed by illegal harvesting in the specified territory. While many agree that rule enforcement is necessary for creating a sustainable resource over time, considerable disagreement exists about who should be the monitors (see, e.g., Bruner et al., 2001; Wells and Brandon, 1992). Simply employing a few guards who cannot get to know the terrain or the people living in an area has not been a successful strategy.

Most long-surviving resource regimes select some of their own monitors, who are accountable to the appropriators or are appropriators themselves and who keep an eye on resource conditions as well as on harvesting activities. By creating official positions for local monitors, a resource regime does not have to rely only on local community norms to sanction a rule breaker. The community creates an official position. In some systems, users rotate into this position so that everyone has a duty to be a monitor. In other systems, all participants contribute resources and they jointly hire monitors. 
In an analysis of results from a study by the International Forestry Resources and Institutions (IFRI) research network of the conditions of forests used by 178 forest user groups located in 12 countries, Gibson, Williams, and Ostrom (2005) found that the level of local monitoring varies substantially across groups. One of the measures obtained in this study is the frequency with which a local group monitors and sanctions rule-breaking behavior in the forest. We examined the impact of this variable on appropriators' assessment of forest conditions (as well as on a forester's assessment). We also examined the impact of a group's social capital, the group’s dependence on forest resources, and whether the group was formally organized or not. The result of the analysis is that regular monitoring by a local group is more important than the other three variables in enhancing forest conditions. Regardless of the levels of social capital, forest dependence, and formal organization, regular monitoring and sanctioning are strongly and statistically associated with better forest conditions (see Hayes and Ostrom, 2005; Coleman, 2009). Chhatre and Agrawal (2009) have just completed a major empirical study of how local autonomy in rule making and forest ownership are positively associated with increased carbon storage.

Some local utilities in the United States are now seeking to reduce energy consumption by developing local monitoring systems whose results are then reported on the bills that customers receive. The Sacramento Municipal Utility District, for example, has tried various techniques, including rebates for energy-saving appliances, but recently found a more effective technique.

Last April (2008), it began sending out statements to 35,000 randomly selected customers, rating them according to their energy use compared with that of neighbors in 100 homes of similar size that used the same heating fuel. The customers were also compared with 20 neighbors who were especially efficient in saving energy. 
Customers who score high earned two smiley faces on their statements. "Good" conservation got a single smiley face. (Kaufman, 2009)

The utility company conducted an initial assessment of this new strategy after using it for six months. The assessment found "that customers who received the personalized report reduced energy use by 2 percent more than those who got standard statements” (ibid.). Using various forms of competition among households and groups and feedback on who is doing the best at reducing energy use is a strategy for reducing emissions that is increasingly being adopted by college campuses, small cities, and utility firms around the country.

Contemporary psychological studies have found that framing problems related to resource use in a social context does affect actions. Schultz et al. (2007) and Mumford (2007) have conducted studies finding that messages containing social references are more effective in changing behavior than messages stressing factual information. For example, statements saying that " $\mathrm{x} \%$ of guests in this hotel recycle towels," instead of specifying the amount of water saved when one recycles, lead to increased levels of recycling.

\section{Complex, Multi-Level Systems to Cope with a Complex, Multi-Level Problem}

Given that the recognition of the danger of climate change among citizens and public officials is still relatively recent, and given the debates about who is responsible for causing the problem and for finding solutions, one cannot expect that an effective polycentric system will be constructed in the near future. But given the slowness and conflict involved in achieving a global solution, recognizing the potential of building even more effective ways of reducing energy use at multiple levels is an important step forward.

Further, one of the important strategies for reducing the level of $\mathrm{CO}_{2}$ in the atmosphere is developing more effective policies for protecting ecosystem services—particularly those related to carbon sequestration. Developing effective and adaptive programs, however, requires 
selecting appropriate areas and developing plans for leaving some areas untouched and for making major investments in the flora and fauna as well as the technological infrastructure of other areas (Michel, 2009). This requires substantial investment in scientific modeling (Nelson et al., 2009). Fortunately, recent breakthroughs in using geographic information systems and indepth knowledge of the biophysical settings to map ecological systems over time are beginning to provide the tools needed for more careful planning for improvements in ecological systems (Daily et al., 2009). The models, however, need to be developed at multiple scales and decisionmaking units so that they can then focus at diverse scales to determine which policies can be adopted to improve carbon sequestration in line with the ecology at that particular scale.

Given the complexity and changing nature of the problems involved in coping with climate change, there are no "optimal" solutions that can be used to make substantial reductions in the level of greenhouse gases emitted into the atmosphere. A major reduction in emissions is, however, needed. The advantage of a polycentric approach is that it encourages experimental efforts at multiple levels, as well as the development of methods for assessing the benefits and costs of particular strategies adopted in one type of ecosystem and comparing these with results obtained in other ecosystems. A strong commitment to finding ways of reducing individual emissions is an important element for coping with climate change. Building such a commitment, and the trust that others are also taking responsibility, can be more effectively undertaken in small- to medium-scale governance units that are linked through information networks and monitoring at all levels. 


\section{References}

Agrawal, Arun. 2000. "Small Is Beautiful, but Is Larger Better? Forest-Management Institutions in the Kumaon Himalaya, India.” In People and Forests: Communities, Institutions, and Governance, ed. Clark Gibson, Margaret McKean, and Elinor Ostrom, 57-86.

Cambridge, MA: MIT Press.

2002. “Common Resources and Institutional Sustainability.” In The Drama of the Commons, National Research Council, Committee on the Human Dimensions of Global Change, ed. Elinor Ostrom, Thomas Dietz, Nives Dolšak, Paul C. Stern, Susan Stonich, and Elke Weber, 41-85. Washington, DC: National Academy Press.

2005. Environmentality: Technologies of Government and Political Subjects. Durham, NC: Duke University Press.

. 2008. “The Role of Local Institutions in Adaptation to Climate Change.” Report submitted to the World Bank, Washington, DC.

Andersen, M. S. 2001. Economic Instruments and Clean Water: Why Institutions and Policy Design Matters. Paris: OECD.

Baer, Paul, John Harte, Barbara Haya, et al. 2000. "Equity and Greenhouse Gas Responsibility.” Science 289(5488) (September 29): 2287.

Bala, G., K. Caldeira, M. Wickett, T. J. Phillips, D. B. Lobell, C. Delire, and A. Mirin. 2007. “Combined Climate and Carbon-Cycle Effects of Large-Scale Deforestation.” Proceedings of the National Academy of Sciences 104(16):6550-55.

Baland, Jean-Marie, and Jean-Philippe Platteau. [1996] 2000. Halting Degradation of Natural Resources: Is There a Role for Rural Communities? New York: Oxford University Press.

Barnes, Peter. 2008. Climate Solutions: A Citizen’s Guide. White River Junction, VT: Chelsea Green Publishing.

Barrett, Scott. 2003. “Global Climate Change and the Kyoto Protocol.” In Environment and Statecraft: The Strategy of Environmental Treaty-Making, ed. Scott Barrett, 359-98. Oxford: Oxford University Press.

Berman, Harold J. 1983. Law and Revolution: The Formation of the Western Legal Tradition. Cambridge, MA: Harvard University Press.

Betsill, Michele M. 2001. "Mitigating Climate Change in US Cities: Opportunities and Obstacles.” Local Environment 6(4):393-406.

Bierbaum, Rosina M. 2008. "Energy and Climate Change.” Bulletin of the American Academy 61(2) (Winter): 32-36. 
Botsen, W. J. W., J. M. Gowdy, and J. C. J. M. Van den Bergh. 2008. “Cumulative $\mathrm{CO}_{2}$ Emissions: Shifting International Responsibilities for Climate Debt.” Climate Policy 8:569-76.

Boyd, Emily. 2009. "Governing the Clean Development Mechanism: Global Rhetoric versus Local Realities in Carbon Sequestration Projects.” Environment and Planning A, forthcoming.

Bruner, Aaron, Raymond Gullison, Richard Rice, and Gustavo da Fonseca. 2001. "Effectiveness of Parks in Protecting Tropical Biodiversity.” Science 291(5501):125-29.

Brondizio, Eduardo S., and Emilio F. Moran. 2008. "Human Dimensions of Climate Change: The Vulnerability of Small Farmers in the Amazon.” Philosophical Transactions of the Royal Society B 363 (February): 1803-9.

Burris, Mark W., and Xu Lei. 2006. "Potential Single-Occupancy Vehicle Demand for HighOccupancy Vehicle Lanes: Results from State-Preference Survey of Travelers in High Occupancy Toll Corridors.” Transportation Research Record 1960:108-18.

Burton, A. 2006. "What Future for Fish.” Frontiers in Ecology and the Environment 4(1):508.

Camerer, Colin F. 2003. Behavioral Game Theory: Experiments in Strategic Interaction. Princeton, NJ: Princeton University Press.

Carraro, C. 2003. Governing the Global Environment. Cheltenham, UK: Edward Elgar.

Chhatre, Ashwini, and Arun Agrawal. 2009. “Trade-Offs and Synergies between Carbon Storage and Livelihood Benefits from Forest Commons.” Proceedings of the National Academy of Sciences, early edition, http://www.pnas.org/content/early/2009/10/05/0905308106.

Chomitz, K. M. 2002. "Baseline, Leakage and Measurement Issues: How Do Forestry and Energy Projects Compare?” Climate Policy 2:35-49.

Clark, Colin W. 2006. The Worldwide Crisis in Fisheries: Economic Models and Human Behavior. Cambridge: Cambridge University Press.

Coleman, Eric. 2009. "Institutional Factors Affecting Ecological Outcomes in Forest Management.” Journal of Policy Analysis and Management 28(1):122-46.

Corbera, Esteve, and Katrina Brown. 2008. "Building Institutions to Trade Ecosystem Services: Marketing Forest Carbon in Mexico.” World Development 36(10) (October): 1956-79.

Costanza, Robert, John Cumberland, Herman Daley, et al. 1997. An Introduction to Ecological Economics. Boca Raton, FL: St. Lucie Press. 
Covington, W. W. 2000. “Helping Western Forests Heal.” Nature 408:135-36.

Cox, James C., Daniel Friedman, and Steven Gjerstad. 2007. "A Tractable Model of Reciprocity and Fairness.” Games and Economic Behavior 59:17-45.

Crawford, Sue E. S., and Elinor Ostrom. 2005. “A Grammar of Institutions.” In Understanding Institutional Diversity, Elinor Ostrom, 137-74. Princeton, NJ: Princeton University Press. Originally published in American Political Science Review 89(3) (September 1995): 582 600.

Daily, Gretchen C., Stephen Polasky, Joshua Goldstein, et al. 2009. "Ecosystem Services in Decision Making: Time to Deliver.” Frontier in Ecology and the Environment 7(1):2128.

Dasgupta, Partha. 2001. Human Well-Being and the National Environment. Oxford: Oxford University Press.

Dellink, Rob, Thijs Dekker, Michael den Elzen, et al. 2009. "Sharing the Burden of Adaptation Financing.” Amsterdam: Institute for Environmental Studies Newsletter, January.

den Elzen, M. G. J., M. Schaeffer, and P. L. Lucas. 2005. "Differentiating Future Commitments on the Basis of Countries' Relative Historical Responsibility for Climate Change: Uncertainties in the 'Brazilian Proposal' in the Context of a Policy Implementation.” Climate Change 71:277-301.

Dietz, Thomas, Elinor Ostrom, and Paul Stern. 2003. "The Struggle to Govern the Commons.” Science 302(5652):1907-12.

Eadson, Will. 2008. “Climate Change Mitigation in Local Area Agreements: An Enforced Lack of Ambition?” People, Place \& Policy Online 2/3:140-50.

Ebeling, Johannes. 2008. "Risks and Criticisms of Forestry-Based Climate Change Mitigation and Carbon Trading." In Climate Change and Forests: Emerging Policy and Market Opportunities, ed. Charlotte Streck, Robert O’Sullivan, Toby Janson-Smith, and Richard Tarasofsky, 43-58. London: Chatham House.

Engel, Kirsten H. 2006. "State and Local Climate Change Initiatives: What Is Motivating State and Local Governments to Address a Global Problem and What Does This Say about Federalism and Environmental Law?” Discussion Paper 06-36. Tucson: University of Arizona, James E. Rogers College of Law, Arizona Legal Studies.

European Environmental Agency (EEA). 2006. Greenhouse Gas Emission Trends and Projections in Europe 2006. Luxembourg: Office for Official Publications of the European Communities. EEA Report No. 9, ISSN 1725-9177.

Fehr, Ernst, and Simon Gächter. 2000. "Fairness and Retaliation: The Economics of Reciprocity.” Journal of Economic Perspectives 14(3):159-81. 
. 2002. “Altruistic Punishment in Humans.” Nature 415:137-40.

Fehr, Ernst, and Andreas Leibbrandt. 2008. “Cooperativeness and Impatience in the Tragedy of the Commons.” IZA Discussion Paper no. 3625, University of Zurich.

Fehr, Ernst, and Bettina Rockenbach. 2003. "Detrimental Effects of Sanctions on Human Altruism.” Nature 422 (March): 137-40.

Fehr, Ernst, and Klaus Schmidt. 1999. “A Theory of Fairness, Competition, and Cooperation.” Quarterly Journal of Economics 114(3):817-68.

Finlayson, A. Christopher. 1994. Fishing for Truth: A Sociological Analysis of Northern Cod Stock Assessment from 1977-1990. St. Johns: Memorial University of Newfoundland, Newfoundland Institution of Social and Economic Research.

Finlayson, A. Christopher, and Bonnie J. McCay. 1998. "Crossing the Threshold of Ecosystem Resilience: The Commercial Extension of Northern Cod.” In Linking Social and Ecological Systems: Management Practices and Social Mechanisms for Building Resilience, ed. Fikret Berkes and Carl Folke, 311-38. Cambridge: Cambridge University Press.

Frey, Bruno S. 2005. “Beyond Traditional Borders: A New Proposal for Federalism.” The Economists’ Voice 2(2): article 9, http://www.bepress.com/ev/vol2/iss2/.

Frohlich, Norman, and Joe A. Oppenheimer. 1992. Choosing Justice: An Experimental Approach to Ethical Theory. Berkeley: University of California Press.

Fule, P. Z., J. E. Crouse, A. E. Cocke, et al. 2004. "Changes in Canopy Fuels and Potential Fire Behavior, 1880-2040.” Ecological Modeling 175:231-48.

Fuller, Merrian C., Stephen C. Portis, and Daniel M. Kammen. 2009. “Toward a Low-Carbon Economy: Municipal Financing for Energy Efficiency and Solar Power.” Environment 51(1):22-32.

Gibson, Clark, Margaret McKean, and Elinor Ostrom, eds. 2000. People and Forests: Communities, Institutions, and Governance. Cambridge, MA: MIT Press.

Gibson, Clark, John Williams, and Elinor Ostrom. 2005. “Local Enforcement and Better Forests.” World Development 33(2):273-84.

Hardin, Garrett. 1968. “The Tragedy of the Commons.” Science 162:1243-48.

Harris, L. 1990. Independent Review of the State of the Northern Cod Stock. Prepared for The Honourable Thomas Siddon, Minister of Fisheries. Ottawa: Communications Directorate, Department of Fisheries and Oceans. 
Hayes, Tanya, and Elinor Ostrom. 2005. “Conserving the World’s Forests: Are Protected Areas the Only Way?” Indiana Law Review 38(3):595-617.

Hess, Charlotte, and Elinor Ostrom, eds. 2007. Understanding Knowledge as a Commons: From Theory to Practice. Cambridge, MA: MIT Press.

Hurteau, Matthew D., George W. Koch, and Bruce A. Hungate. 2008. “Carbon Protection and Fire Risk Reduction: Toward a Full Accounting of Forest Carbon Offsets.” Frontiers in Ecological Environment 6(9):493-98.

Intergovernmental Panel on Climate Change. 2007. Climate Change 2007: Mitigation of Climate Change. Cambridge: Cambridge University Press.

Kates, Robert W., and Thomas J. Wilbanks. 2003. "Making the Global Local: Responding to Climate Change Concerns from the Ground Up.” Environment 45(3):12-23.

Kaufman, Leslie. 2009. “A Desire to Keep Up with Neighbors is Spurring Conservation.” New York Times. January 30.

Lichbach, Mark Irving. 1996. The Cooperator’s Dilemma. Ann Arbor: University of Michigan Press.

Lohmann, L. 2008. "Carbon Trading, Climate Justice and the Production of Ignorance: Ten Examples.” Development 51(3):359-65.

Luce, R. Duncan, and Howard Raiffa. 1957. Games and Decisions: Introduction and Critical Survey. New York: Wiley.

Matthews, H. D., and K. Caldeira. 2008. "Stabilizing Climate Requires Near Zero Emissions.” Geophysical Research Letters 35:1-5.

McKean, Margaret A. 2000. "Common Property: What Is It, What Is It Good For, and What Makes It Work.” In People and Forests: Communities, Institutions, and Governance, ed. Clark C. Gibson, Margaret A. McKean, and Elinor Ostrom, 27-55. Cambridge, MA: MIT Press.

Meserve, Richard A. 2008. “An Introduction to Energy and Climate Change.” Bulletin of the American Academy (Winter): 29-32.

Michel, David. 2009. “Foxes, Hedgehogs, and Greenhouse Governance: Knowledge, Uncertainty, and International Policy-Making in a Warming World.” Applied Energy 86:258-64.

Milinski, Manfred, Dirk Semmann, and Hans-Jürgen Krambeck. 2002. "Reputation Helps Solve the 'Tragedy of the Commons.'” Nature 415 (January 24): 424-26. 
Miller, Clark A. 2004. "Climate Science and the Making of a Global Political Order.” In States of Knowledge: The Coproduction of Science and Social Order, ed. Sheila Jasanoff, 4666. New York: Routledge.

Mintrom, Michael. 2000. Policy Entrepreneurs and School Choice. Washington, DC: Georgetown University Press.

Mumford, G. 2007. “Psychology’s Ability to Curb Energy Use.” Monitor on Psychology 38(11):20-21.

Najam, A., S. Huq, and Y. Sokona. 2003. "Climate Negotiations beyond Kyoto: Developing Countries Concerns and Interests.” Climate Policy 3:221-31.

Nelson, Erik, Guillermo Mendoza, James Regetz, et al. 2009. "Modeling Multiple Ecosystem Services, Biodiversity Conservation, Commodity Production, and Tradeoffs at Landscape Scales.” Frontiers in Ecology and the Environment 7(1):4-11.

Nelson, Erik, Stephen Polasky, David J. Lewis, et al. 2008. "Efficiency of Incentives to Jointly Increase Carbon Sequestration and Species Conservation on a Landscape.” Proceedings of the National Academy of Sciences 105(28):9471-76.

Netting, Robert McC. 1981. Balancing on an Alp: Ecological Change and Continuity in a Swiss Mountain Community. New York: Cambridge University Press.

NRC (National Research Council). 1986. Proceedings of the Conference on Common Property Resource Management. Washington, DC: National Academy Press. 2002. The Drama of the Commons. Committee on the Human Dimensions of Global Change. Elinor Ostrom, Thomas Dietz, Nives Dolšak, Paul Stern, Susan Stonich, and Elke Weber, eds. Washington, DC: National Academy Press.

Normille, Dennis. 2009. “Tracking $\mathrm{CO}_{2}$ 's Comings and Goings from Space.” Science 323 (January 16): 325.

Odion, D. C., and C. T. Hanson. 2006. "Fire Severity in Conifer Forests of the Sierra Nevada, California.” Ecosystems 9:1177-89.

Olson, Mancur. 1965. The Logic of Collective Action: Public Goods and the Theory of Groups. Cambridge, MA: Harvard University Press.

Oppenheimer, Michael, Brian C. O’Neill, and Mort Webster. 2008. "Negative Learning.” Climatic Change 89:155-72.

Opschoor, Johannes Baptist, K. Button, and P. Nijkamp, eds. 1999. Environmental Economics and Development. Cheltenham, UK: Edward Elgar. 
Ostrom, Elinor. 1990. Governing the Commons: The Evolution of Institutions for Collective Action. New York: Cambridge University Press.

. 1992. "The Rudiments of a Theory of the Origins, Survival, and Performance of Common-Property Institutions.” In Making the Commons Work: Theory, Practice, and Policy, ed. Daniel W. Bromley et al., 293-318. San Francisco, CA: ICS Press.

. 1998. "A Behavioral Approach to the Rational Choice Theory of Collective Action." American Political Science Review 92(1):1-22.

. 2001. "Reformulating the Commons." In Protecting the Commons: A Framework for Resource Management in the Americas, ed. Joanna Burger, Elinor Ostrom, Richard Norgaard, David Policansky, and Bernard Goldstein, 17-41. Washington, DC: Island Press.

. 2005. Understanding Institutional Diversity. Princeton, NJ: Princeton University Press.

. 2007. “A Diagnostic Approach for Going beyond Panaceas.” Proceedings of the National Academy of Sciences 104:15181-87.

Ostrom, Elinor, Roy Gardner, and James Walker. 1994. Rules, Games, and Common-Pool Resources. Ann Arbor: University of Michigan Press.

Ostrom, Elinor, and Harini Nagendra. 2006. "Insights on Linking Forests, Trees, and People from the Air, on the Ground, and in the Laboratory." Proceedings of the National Academy of Sciences 103(51):19224-31.

Ostrom, Elinor, Roger B. Parks, and Gordon P. Whitaker. 1978. Patterns of Metropolitan Policing. Cambridge, MA: Ballinger.

Ostrom, Vincent. 1999. “Polycentricity_Part 1.” In Polycentricity and Local Public Economies, ed. Michael McGinnis, 52-74. Ann Arbor: University of Michigan Press.

. 2008a. The Intellectual Crisis in American Public Administration. 3rd ed. Tuscaloosa: University of Alabama Press.

. 2008b. The Political Theory of a Compound Republic: Designing the American Experiment. 3rd ed. Lanham, MD: Lexington Books.

Ostrom, Vincent, Charles M. Tiebout, and Robert Warren. 1961. "The Organization of Government in Metropolitan Areas: A Theoretical Inquiry.” American Political Science Review 55(4) (December): 831-842.

O’Sullivan, Robert. 2008. “Reducing Emissions from Deforestation in Developing Countries.” In Climate Change and Forests: Emerging Policy and Market Opportunities, ed. Charlotte Streck, Robert O’Sullivan, Toby Janson-Smith, and Richard Tarasofsky, 179-90. London: Chatham House. 
Paavola, Jouni. 2008a. "Science and Social Justice in the Governance of Adaptation to Climate Change.” Environmental Politics 17(4):644-59.

. 2008b. "Governing Atmospheric Sinks: The Architecture of Entitlements in the Global Commons.” International Journal of the Commons 2(2):313-36.

Pope, C. Arden, Majid Ezzati, and Douglas W. Dockery. 2009. "Fine-Particulate Air Pollution and Life Expectancy in the United States.” New England Journal of Medicine 360(4):376-86.

Posner, Eric A., and Cass Sunstein. 2008. “Justice and Climate Change.” Discussion Paper 0804. Cambridge, MA: Harvard University Project on International Climate Agreements.

Poteete, Amy, Marco Janssen, and Elinor Ostrom. Forthcoming. Working Together: Collective Action, the Commons, and Multiple Methods in Practice. Particularly relevant is chapter 10: "Beyond the Conventional Theory of Collective Action and the Commons."

Pritchett, Lant, and Michael Woolcock. 2003. "Solutions When the Solution Is the Problem: Arraying the Disarray in Development.” World Development 35(3):435-61.

Rothstein, Bo. 1998. Just Institutions Matter: The Moral and Political Logic of the Universal Welfare State. Cambridge: Cambridge University Press. . 2005. Social Traps and the Problem of Trust. Cambridge: Cambridge University Press.

Sandler, Todd. 1997. Global Challenges: An Approach to Environmental, Political and Economic Problems. Cambridge: Cambridge University Press. . 2004. Global Collective Action. Cambridge: Cambridge University Press.

Sandler, Todd, and Daniel G. Arce M. 2003. "Pure Public Goods versus Commons.” Land Economics 79(3):355-68.

Schelling, Thomas C. 1978. Micromotives and Macrobehavior. New York: Norton.

Schlager, Edella. 1994. "Fishers’ Institutional Responses to Common-Pool Resource Dilemmas.” In Rules, Games, and Common-Pool Resources, ed. Elinor Ostrom, Roy Gardner, and James M. Walker, 247-66. Ann Arbor: University of Michigan Press.

Schlager, Edella, William Blomquist, and Shui Yan Tang. 1994. "Mobile Flows, Storage and Self-Organized Institutions for Governing Common-Pool Resources.” Land Economics 70(3) (August): 294-317.

Schlager, Edella, and Elinor Ostrom. 1992. "Property-Rights Regimes and Natural Resources: A Conceptual Analysis.” Land Economics 68(3) (August): 249-69. 
Schultz, P., J. Nolan, R. Cialdini, et al. 2007. "The Constructive, Destructive, and Reconstructive Power of Social Norms.” Psychological Science 18(5):429-34.

Sen, Amartya. 1977. "Rational Fools: A Critique of the Behavioral Foundations of Economic Theory." Philosophy and Public Affairs 6(4):317-44.

Sovacool, Benjamin K. 2008. "The Best of Both Worlds: Environmental Federalism and the Need for Federal Action on Renewal Energy and Climate Change.” Stanford Environmental Law Journal 27:397-473.

Sovacool, Benjamin K., and Marilyn A. Brown. 2009a. "Addressing Climate Change: Global and Local?” In Generating Electricity in a Carbon Constrained World, ed. Fereidoon P. Sioshansi. New York: Elsevier. 2009b. "Scaling the Policy Response to Climate Change.” Policy and Society 27(4):31728.

Stavins, Robert. 1997. "Policy Instruments for Climate Change: How Can National Governments Address a Global Problem?” University of Chicago Legal Forum, volume 1997: Rethinking Environmental Protection for the 21st Century, 293-329.

Stern, Nicholas. 2007. The Economics of Climate Change: The Stern Review. Cambridge: Cambridge University Press.

Streck, Charlotte, Robert O’Sullivan, Toby Janson-Smith, and Richard Tarosofsky, eds. 2008. Climate Change and Forests: Emerging Policy and Market Opportunities. London: Chatham House.

Toonen, Theo A.J. 1996. "On the Administrative Condition of Politics: Administrative Transformation in the Netherlands." West European Politics 19(3): 609-32.

UN-Habitat. 2008. Cities and Climate Change Adaptation. Prepared for the UN-Habitat Donors Meeting, Seville, October 15-16, 2008.

United Nations. 1982. Final Act of the Third Conference on the Law of the Seas. Montenegro Bay, Jamaica: United Nations.

Vandenberg, Michael P., and Anne C. Steinemann. 2007. “The Carbon-Neutral Individual.” New York University Law Review 82 (December): 1673-741.

Vatn, Arild. 2005. Institutions and the Environment. Cheltenham, UK: Edward Elgar.

Wade, Robert. 1994. Village Republics: Economic Conditions for Collective Action in South India. San Francisco, CA: ICS Press.

Walters, Carl J. 1986. Adaptive Management of Renewable Resources. New York: Macmillan. 
Wara, Michael. 2007. “Is the Global Carbon Market Working?” Nature 445 (February 8): 59596.

Wara, Michael, and David G. Victor. 2008. "A Realistic Policy on International Carbon Offsets.” Working Paper no. 74. Stanford, CA: Stanford University Program on Energy and Sustainable Development.

Wells, Michael, and Katrina Brandon. 1992. People and Parks: Linking Protected Area Management with Local Communities. Washington, DC: World Bank.

Wiener, Jonathan B. 2007. "Think Globally, Act Globally: The Limits of Local Climate Policies.” University of Pennsylvania Law Review 155:1961-79.

Wilson, Doug. 2006. “Predictions about European Commons.” The Common Property Resource Digest 77:7-8.

Wilson, James. 2002. "Scientific Uncertainty, Complex Systems, and the Design of CommonPool Institutions." In The Drama of the Commons, National Research Council, Committee on the Human Dimensions of Global Change, ed. Elinor Ostrom, Thomas Dietz, Nives Dolšak, Paul C. Stern, Susan Stonich, and Elke U. Weber, 327-59. Washington, DC: National Academy Press.

Wilson, James, James Acheson, Mark Metcalfe, and Peter Kleban. 1994. "Chaos, Complexity, and Community Management of Fisheries.” Marine Policy 18:291-305.

Wilson, James, Liying Yan, and Carl Wilson. 2007. "The Precursors of Governance in the Maine Lobster Fishery.” Proceedings of the National Academy of Sciences 104(39):15212-17. 


\section{APPENDIX A}

\section{A Brief Overview of the Studies of Polycentric Provision of Public Goods in Metropolitan Areas}

Among the major public goods provided at an urban level are public safety and education. During the 1970s and 1980s, in response to concerns about police and school effectiveness, proposals to slash the number of police departments and school districts serving urban and rural areas of the United States were placed on the national agenda. Underlying these proposals was the assumption that "bigger is always better." Some proposals recommended the reduction of the more than 40,000 police departments that then existed in the United States to around 400 police departments for the entire country. Other recommendations proposed massive consolidation of school districts, and many efforts to achieve this consolidation were successful even though voters did not approve most of these administrative reforms. No systematic empirical evidence supported reform proposals related to moving the provision of public goods from smaller-scale units to larger governments. This appendix provides a brief overview of the findings from a major set of studies conducted by researchers associated with the Workshop in Political Theory and Policy Analysis at Indiana University regarding the polycentric provision of policing in metropolitan areas of the United States and a very brief overview of more recent studies related to other urban public goods.

\section{Polycentricity and Police}

\section{Small and Medium-Size Police Agencies Are More Effective in Producing Direct Services}

One of the first sets of studies measured the performance of diversely sized police agencies serving similar communities in the Indianapolis, Chicago, St. Louis, Rochester, and Tampa-St. 
Petersburg metropolitan areas. The severe challenge of measuring police performance was met by collecting performance data from interviews with a random sample of households served by small, medium-size, and large departments. Information was obtained about victimization, willingness to call the police, speed of police response, amount of police follow-up, satisfaction levels with police contacts, and general evaluations of the quality of policing in a neighborhood. By studying matched neighborhoods with similar service conditions, we controlled for many of the other factors that can be expected to affect performance.

The consistent finding from this series of studies was that small and medium-size police departments perform more effectively, and frequently at lower costs, than large police departments serving similar neighborhoods (see McGinnis, 1999). Victimization rates tend to be lower, police response tends to be faster, citizens tend to be more willing to call the police, citizens tend to more positively evaluate specific contacts with the police, and citizens tend to rate police higher across a series of evaluative questions.

\section{Small Police Agencies Arrange for Indirect Services from Large Police Agencies}

In our major study of police organization in 80 metropolitan areas (Ostrom et al., 1978), a total of 1,159 direct-service producers were found to produce services directly for the residents in the areas. Most of these agencies produced general area patrol, traffic patrol, accident investigation, and burglary investigation services. In regard to indirect services, we found that 70 percent of the direct-service producers also produced their own radio communications, but only a small proportion of any of the direct-service producers produced the other indirect services, such as crime labs or entry-level training. In all 80 Standard Metropolitan Statistical Areas, indirect services were made available to all direct-service producers. 


\section{Police Performance Enhanced in Metropolitan Areas with Larger Numbers}

\section{of Police Agencies}

In order to examine the effect of interorganizational arrangements on police performance, we relied on measures of performance such as the allocation of police personnel to on-the-street assignments and the relative efficiency of agencies in producing response capacity and solving crime. For each of the 80 metropolitan areas, we calculated the number of producers of each type of service (multiplicity) and the proportion of the population being served by the largest producer of each type of service (dominance). Metropolitan areas with low scores in multiplicity and high scores in dominance come closest to approximating the "consolidated" model. Metropolitan areas with high scores in multiplicity and low scores in dominance come closest to approximating the "fragmented" metropolitan area so strongly criticized in the policy literature.

We found a distinct difference in the availability of sworn officers to conduct patrols in the metropolitan areas depending upon the structure of interorganizational arrangements. While more officers per capita were employed in the most consolidated areas, a lower percentage of these officers were actually assigned to patrol divisions in these metropolitan areas. One-third more officers were required in the most consolidated metropolitan areas to place the same number of officers on patrol as compared with the least consolidated metropolitan areas. Citizens living in the most fragmented metropolitan areas received more police presence on the streets for their tax expenditures than did citizens living in the most consolidated areas (Parks, 1985).

\section{Polycentricity and Other Urban Public Goods}

Other research has been undertaken since the early police studies that strongly supports the findings of those studies. In addition to the research on police, scholars have conducted rigorous empirical research that has challenged the presumptions that larger public school districts 
achieve higher performance (Hanushek, 1986; Teske et al., 1993) and that fragmentation of governments leads to higher costs (Dilorenzo, 1983; Schneider, 1986; Boyne, 1992), and that has provided further insights into the way local governments are constituted (Oakerson and Parks, 1989; Stephens and Wikstrom, 2000). As a result of extensive empirical and theoretical research, the presumed self-evident truth that constructing one government for each metropolitan area is the best way to achieve efficiency and equity has slowly been replaced by a recognition that judging "structure directly on the single criterion of uniformity contributes little to the advancement of research or reform” (Oakerson, 1999: 117). Instead of a single best design that would have to cope with the wide variety of problems faced in different localities, a polycentric theory generates core principles that can help in the design of effective local institutions when used by informed and interested citizens and public officials.

In his conclusion to an in-depth study of the adverse effects of urban consolidation efforts in the United States and Canada during the last century, Andrew Sancton (2000: 167) reflected that,

Municipalities are more than just providers of services. They are the democratic mechanisms through which territorially based communities of people govern themselves at a local level. ... Those who would force municipalities to amalgamate with each other invariably claim that their motive is to make municipalities stronger. Such an approachhowever well-intentioned - erodes the foundations of our liberal democracies because it undermines the notion that there can be forms of self-government that exist outside the institutions of the central government. ...

Thus scholars, public officials, and citizens who are concerned with solving collective action problems effectively, equitably, and efficiently, recognize the importance of authorizing citizens to constitute their own local jurisdictions and associations using the knowledge and experience they have about the public problems they face. 


\section{References to Appendix A}

Boyne, G. 1992. “Local Government Structure and Performance: Lessons from America.” Public Administration 70:333-57.

Dilorenzo, T. 1983. “Economic Competition and Political Competition: An Empirical Note.” Public Choice 40:203-9.

Hanushek, E. A. 1986. "The Economics of Schooling: Production and Efficiency in Public Schools.” Journal of Economic Literature 24:1141-77.

McGinnis, Michael, ed. 1999. Polycentricity and Local Public Economies: Readings from the Workshop in Political Theory and Policy Analysis. Ann Arbor: University of Michigan Press.

Oakerson, Ronald. 1999. Governing Local Public Economies: Creating the Civic Metropolis. Oakland, CA: ICS Press.

Oakerson, Ronald, and Roger Parks. 1989. "Local Government Constitutions: A Different View of Metropolitan Governance.” American Review of Public Administration 19(4):279-84.

Ostrom, Elinor, Roger Parks, and Gordon Whitaker. 1978. Patterns of Metropolitan Policing. Cambridge, MA: Ballinger.

Parks, Roger. 1985. "Metropolitan Structure and Systemic Performance: The Case of Police Service Delivery.” In Policy Implementation in Federal and Unitary Systems, ed. Kenneth Hanf and Theo A. J. Toonen, 161-91. Dordrecht, Netherlands: Martinus Nijhoff.

Sancton, Andrew. 2000. The Assault on Local Government. Montreal: McGill-Queen’s University Press.

Schneider, Mark. 1986. “Fragmentation and the Growth of Government.” Public Choice 48:25563.

Stephens, G. R., and N. Wikstrom. 2000. Metropolitan Government and Governance: Theoretical Perspectives, Empirical Analysis, and the Future. New York: Oxford University Press.

Teske, Paul, Mark Schneider, Michael Mintrom, and Samuel Best. 1993. "Establishing the Micro Foundations of a Macro Theory: Information, Movers, and the Competitive Local Market for Public Goods.” American Political Science Review 87(3):702-13. 